\title{
MODEL PENGAMBILAN KEPUTUSAN PENERIMA BEASISWA CSR UNIVERSITAS BINA INSAN MENGGUNAKAN PROFILE MATCHING
}

\author{
Ali Amran 1 , Bunga Intan ${ }^{2}$, Lukman Sunardi ${ }^{3}$ \\ 1,3Program Studi Informatika, Universitas Bina Insan, Lubuklinggau \\ ${ }^{2}$ Program Studi Sistem Informasi, Universitas Bina Insan, Lubuklinggau \\ e-mail:*1aliamran@univbinainsan.ac.id, ${ }^{2}$ bungaintan@univbinainsan.ac.id, \\ 3lukmansunardi@univbinainsan.ac.id
}

\begin{abstract}
Abstrak
Pendidikan merupakan poros utama kemajuan suatu bangsa serta memiliki posisi yang strategis bagi kehidupan manusia. Semakin baik mutu pendidikan, maka akan semakin pesat kemajuan sebuah bangsa, begitu pula sebaliknya. Keberhasilan pendidikan akan tercapai jika ada usaha untuk meningkatkan mutu pendidikan. Universitas Bina Insan merupakan salah satu lembaga penyelenggara pendidikan tinggi yang ada di Kota Lubuklinggau. Saat ini Universitas Bina Insan memiliki empat fakultas dengan delapan program studi. Program Beasiswa Corporate Social Responsibility (CSR) Universitas Bina Insan adalah salah satu upaya pemberian beasiswa kepada calon mahasiswa lulusan Sekolah Menengah Atas (SMA) atau sederajat yang memiliki nilai akademik bagus tetapi memiliki keterbatasan ekonomi untuk melanjutkan ke perguruan tinggi. Permasalahan yang muncul saat ini adalaj metode yang digunakan dalam menentukan penerima beasiswa Corporate Social Responsibility (CSR) Universitas Bina Insan dilakukan secara manual atau proses penentuan penerima beasiswa CSR dilakukan dengan melihat indicator penilaian seperti nilai akademik dan kondisi ekonomi yang diinput secara manual. Hal ini mengakibatkan proses penilaian membutuhkan waktu yang lama dan tidak terdokumentasi dengan baik. Untuk mengatasi masalah yang ada maka dibutuhkan sebuah sistem aplikasi berbasis computer dan menggunaan metode yang dapat digunakan untuk membantu menyeleksi calon mahasiswa penerima beasiswa Corporate Social Responsibility (CSR). Sistem tersebut dinamakan Sistem pendukung keputusan dan metode yang digunakan adalah Profile Matching.
\end{abstract}

Kata kunci : CSR; SPK; Profile Matching; Beasiswa

\begin{abstract}
Education is the main axis of progress of a nation and has a strategic position for human life. The better the quality of education, the more rapid the progress of a nation will be, and vice versa. The success of education will be achieved if there are efforts to improve the quality of education. Bina Insan University is one of the higher education providers in the City of Lubuklinggau. Currently, Bina Insan University has four faculties with eight study programs. The Bina Insan University Corporate Social Responsibility (CSR) Scholarship Program is an effort to provide scholarships to prospective high school (SMA) graduates or equivalent students who have good academic grades but have economic limitations to continue to higher education. The problem that arises at this time is the method used in determining the recipients of Bina Insan University Corporate Social Responsibility (CSR) scholarships is done manually or the process of determining CSR scholarship recipients is carried out by looking at assessment indicators such as academic scores and economic conditions which are inputted manually. This resulted in the assessment process taking a long time and was not well documented. To solve the existing problem, we need a computer-based application system and use a method that can be used to help select prospective students who receive Corporate Social Responsibility (CSR) scholarships. The system is called a decision support system and the method used is Profile Matching.
\end{abstract}

Keywords : CSR; SPK; Profile Matching; Scholarship 


\section{PENDAHULUAN}

Fungsi dan tujuan pendidikan menurut UU Nomor 20 Tahun 2003 pasal 3 bahwa: Pendidikan nasional berfungsi mengembangkan kemampuan dan membentuk watak serta peradaban bangsa yang bermartabat dalam rangka mencerdaskan kehidupan bangsa [1]. Pendidikan dapat diberikan melalui pendidikan formal, informal ataupun non formal. Sekolah maupun perguruan tinggi sebagai lembaga pendidikan formal harus mampu bersaing, dengan selalu meningkatkan mutu pendidikan agar menghasilkan pendidikan yang berkualitas. Namun saat ini, pendidikan yang berkualitas identik dengan biaya yang cukup tinggi, sehingga tidak semua masyarakat dapat merasakan pendidikan yang berkualitas. Oleh karena itu, untuk menghilangkan jurang pemisah antara masyarakat ekonomi menengah atas dengan masyarakat ekonomi menengah bawah dalam memperoleh pendidikan yang berkualitas, maka diadakanlah pemberian beasiswa.

Universitas Bina Insan merupakan salah satu lembaga penyelenggara pendidikan tinggi yang ada di Kota Lubuklinggau. Saat ini Universitas Bina Insan memiliki empat fakultas dan delapan program studi dengan jumlah total mahasiswa adalah 3200 mahasiswa. Program Beasiswa CSR Universitas Bina Insan adalah salah satu upaya pemberian beasiswa kepada calon mahasiswa lulusan Sekolah Menengah Atas (SMA) dan sederajat yang memiliki nilai akademik bagus tetapi memiliki ketebatasan dalam ekonomi untuk melanjutkan ke perguruan tinggi. Pada tahun ajaran 2018/2019 jumlah calon mahasiswa yang mengikuti program CSR adalah 28 orang dan yang diterima berjumlah 6 orang, sedangkan tahun ajaran 2019/2020 jumlah calon mahasiswa yang mengikuti program CSR adalah 35 orang dan yang diterima berjumlah 30 orang.
Permasalahan yang muncul saat ini adalah metode yang digunakan dalam menentukan penerima beasiswa Corporate Social Responsibility (CSR) Universitas Bina Insan dilakukan secara manual atau proses penentuan penerima beasiswa CSR dilakukan dengan melihat indicator penilaian seperti nilai akademik dan kondisi ekonomi yang diinput secara manual. Hal ini mengakibatkan proses penilaian membutuhkan waktu yang lama dan tidak terdokumentasi dengan baik. Untuk mengatasi masalah yang ada maka dibutuhkan sebuah system aplikasi berbasis computer dan menggunaan metode yang dapat digunakan untuk membantu menyeleksi calon mahasiswa penerima beasiswa Corporate Social

$$
\text { Responsibility(CSR). }
$$

Sistem tersebut dinamakan Sistem pendukung keputusan dan metode yang digunakan adalah Profile Matching. Konsep metode Profile Matching adalah membandingkan antara individu berdasarkan kriteria penilaian sehingga dapat diketahui perbedaan nilainya (disebut juga gap), semakin kecil gap yang dihasilkan maka bobot nilainya semakin besar yang berarti memiliki peluang lebih besar untuk seseorang mendapatkan beasiswa tersebut. Ada beberapa penelitian serupa yang dijadikan sebagai referensi oleh peneliti, salah satunya yaitu oleh [2] dengan judul penelitian Penerapan Metode profile Matching pada Sistem pendukung keputusan pemilihan ketua Program Studi(Studi Kasus : program Studi teknik Informatika STMIK Musi Rawas). Pada penelitian tersebut disebutkan bahwa Konsep metode Profile Matching adalah membandingkan antara kompetensi individu kedalam kompetensi jabatan sehingga dapat diketahui perbedaan kompetensinya (disebut juga gap), semakin kecil gap yang dihasilkan maka bobot nilainya semakin besar yang berarti memiliki peluang lebih besar untuk 
seseorang menempati posisi tersebut. Hasil akhir dari penelitian ini adalah didapatkan informasi peringkat dari setiap calon ketua Program Studi dengan didasarkan pada perhitungan Profile Matching.

\section{TINJAUAN PUSTAKA}

\subsection{Beasiswa}

Beasiswa merupakan suatu bantuan untuk membantu pelajar atau mahasiswa yang masih sekolah atau kuliah supaya mereka bisa menyelesaikan tugasnya dalam mencari ilmu pengetahuan sampai selesai. Beasiswa dalam bentuk bantuan dapat berupa dana sebagai penunjang biaya yang harus dikeluarkan oleh pelajar atau mahasiswa selama menempuh masa pendidikan di tempat belajar [3]. Dengan kata lain, beasiswa adalah bentuk penghargaan yang diberikan kepada individu agar dapat melanjutkan pendidikan ke jenjang yang lebih tinggi [4]. Penghargaan tersebut bisa berbentuk akses tertentu pada suatu instansi atau penghargaan berupa bantuan keuangan

\subsection{Sistem Pendukung Keputusan}

Sistem merupakan jaringan kerja dari prosedur-prosedur yang saling berhubungan, berkumpul bersama-sama untuk melakukan suatu kegiatan atau menyelesaikan suatu sasaran tertentu [5].

Dalam DSS pengambilan keputusan melalui beberapa tahap, antara lain [6]: 1). Penelusuran, 2). Perancangan, 3). Pemilihan, 4). Implementasi;

\subsection{Profile Matching}

Profile matching atau yang biasa disebut dengan Analisis GAP Kompetensi adalah sebuah mekanisme pengambilan keputusan dengan mengasumsikan bahwa terdapat tingkat variabel prediktor yang ideal yang harus dimiliki oleh pelamar, bukannya tinggkat minimal yang harus dipenuhi atau dilewati [7].
Tahapan dalam metode profile matching adalah sebagai berikut:

- Menentuan Bobot Nilai Gap.

- Langkah kedua dengan melakukan pemetaan Gap.

- Melakukan pencocokan dengan tabel bobot.

- Melakukan perhitungan core factor dan secondary factor.

- Setelah menentukan bobot nilai gap untuk ketiga aspek, yaitu aspek kecerdasan, sikap kerja, dan perilaku dengan cara yang sama, setiap aspek dikelompokkan menjadi 2 kelompok yaitu: "Core

Factor " dan "Secondary Factor". Persamaan (1) menampilkan formula perhitungan core factor dan persamaan (2)

$$
\mathrm{NCF}=\frac{\sum \mathrm{NC}(\mathrm{i}, \mathrm{s}, \mathrm{p})}{\sum \mathrm{IC}}
$$

Secondary factor: NSF $=\frac{\sum \text { NS (i, s, p ) }}{\sum \text { IS }}$ factor. perhitungan secondary

- Perhitungan nilai total dengan rumus sebagai berikut :

Berikutnya dihitung nilai total berdasarkan presentase dari core factor dan secondary factor dengan rumus:

\section{$(x) \% . N C F\left(i, s_{0} p\right)+(x) \% . N S F\left(i, s_{0} p\right)=N\left(i, s_{0} p\right)$}

(3)

- Hasil akhir dari proses profile matching adalah ranking dari kandidat yang diajukan untuk mengisi suatu jabatan tertentu. Penentuan ranking mengacu pada hasil perhitungan tertentu.

Ranking $=(\mathrm{x}) \% . \mathrm{Ni}+(\mathrm{x}) \% . \mathrm{Ns}+(\mathrm{x}) \% . \mathrm{Np}$

(4) 


\subsection{Database}

Basis data adalah sebagai kumpulan terorganisasi dari data-data yang berhubungan sedemikian rupa sehingga mudah disimpan, dimanipulasi serta dipanggil oleh pengguna [8].

\section{METODOLOGI PENELITIAN}

Metode pengembangan sistem yang digunakan peneliti adalah metode Waterfall, Alasan digunakan metode ini dikarenakan langkah-langah metode Waterfall sesuai dengan rancangan peneliti. Dimana dalam pengembangan ini peneliti merancang dan membangun sistem secara bertahap. Adapun tahapan yang dilakukan dalam penelitian ini adalah sebagai berikut:

\subsection{Analisis Sistem}

Pada tahap ini dilakukan penelitian langsung ke tempat penelitian dan wawancara dengan bidang kemahasiswaan Universitas Bina Insan.

\subsection{Desain Sistem}

Desain system menggunakan diagram Data Flow Diagram (DFD), dan representasi antarmuka yang akan diimplementasikan menjadi program pada tahap selanjutnya. Gambar 1 menyajikan desain diagram konteks system.

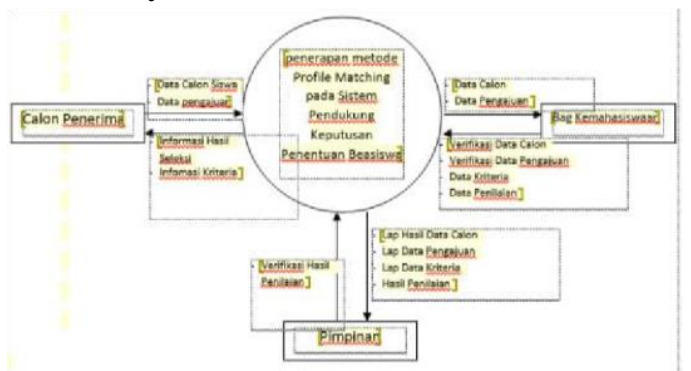

Gambar 1. Diagram Konteks

\subsection{Pembuatan Coding}

Disini peneliti melakukan pengkodean (coding), untuk membuat program sesuai dengan desain sistem sebelumnya. Hasil dari tahap ini adalah program komputer yang sesuai dengan desain yang telah dibuat pada tahap desain.

\subsection{Pengujian}

Setelah sistem baru dibuat, maka akan dilakukan pengujian untuk meminimalisir kesalahan (error) dan memastikan hasil program yang dibuat sesuai dengan yang diinginkan.

\section{HASIL DAN PEMBAHASAN}

Berdasarkan hasil analisa yang dilakukan, dalam proses penentuan penerima bantuan CSR dengan metode profile matching ini, ada 9 Kriteria dapat digunakan yaitu:

Tabel 1. Kriteria Penilaian

\begin{tabular}{|c|l|}
\hline No & \multicolumn{1}{|c|}{ Kriteria Penilaian } \\
\hline 1 & Nilai NEM \\
\hline 2 & Prestasi akademik \\
\hline 3 & Prestasi Non akademik \\
\hline 4 & Pendidikan ayah \\
\hline 5 & Pekerjaan ayah \\
\hline 6 & Pendidikan ibu \\
\hline 7 & Pekerjan ibu \\
\hline 8 & Total penghasilan orang tua \\
\hline 9 & Jumlah_saudara \\
\hline
\end{tabular}

\subsection{Tampilan Input}

Sistem ini dibangun menggunakan Bahasa Pemrograman Visual Basic. Berikut disajikan tampilan input dan output dari sistem.

1 Halaman Utama

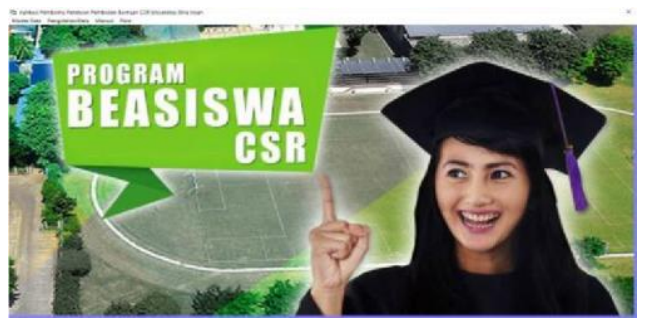

Gambar 2. Desain Halaman Utama 
2 Halaman Input Data Calon

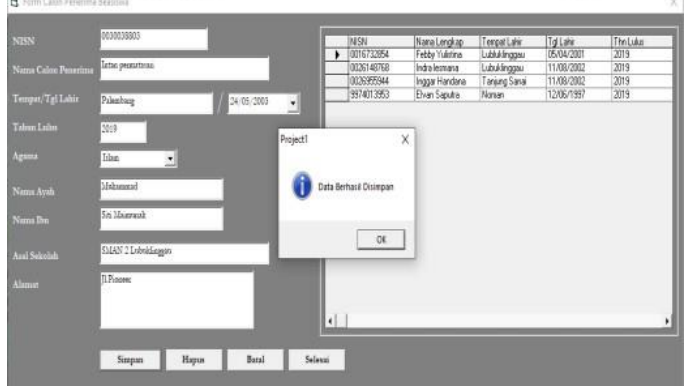

Gambar 3. Desain Input Data Calon

3 Halaman Input Nilai

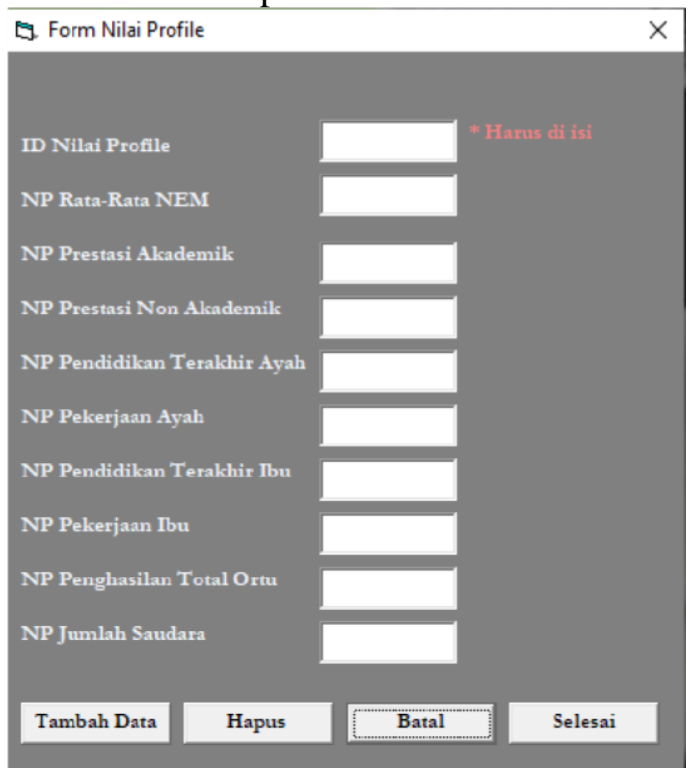

Gambar 4. Desain Input Data Nilai Profile

4 Halaman Input Data Pengajuan

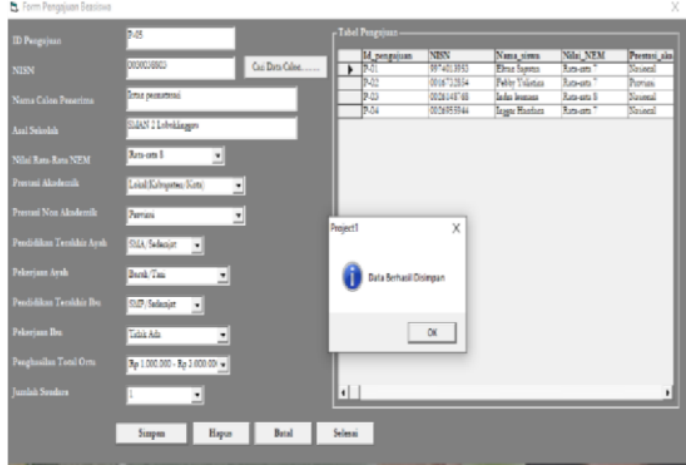

Gambar 5. Desain Halaman Data Pengajuan
5 Halaman Perhitungan GAP

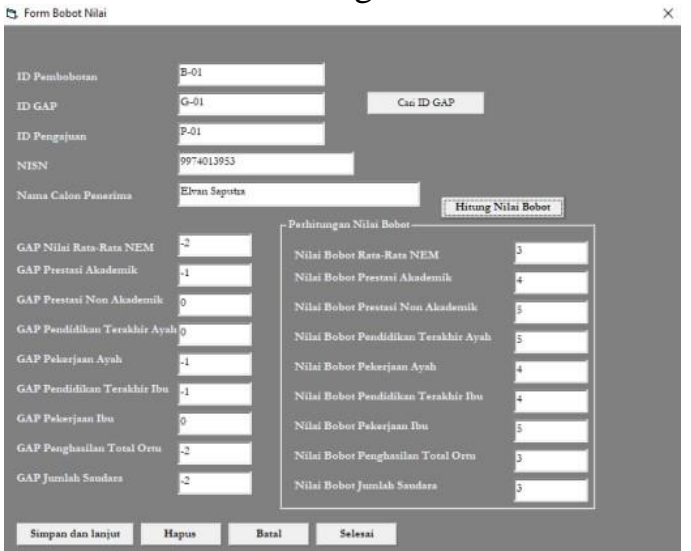

Gambar 6. Desain Halaman Perhitungan GAP

6 Halaman Perhitungan Bobot

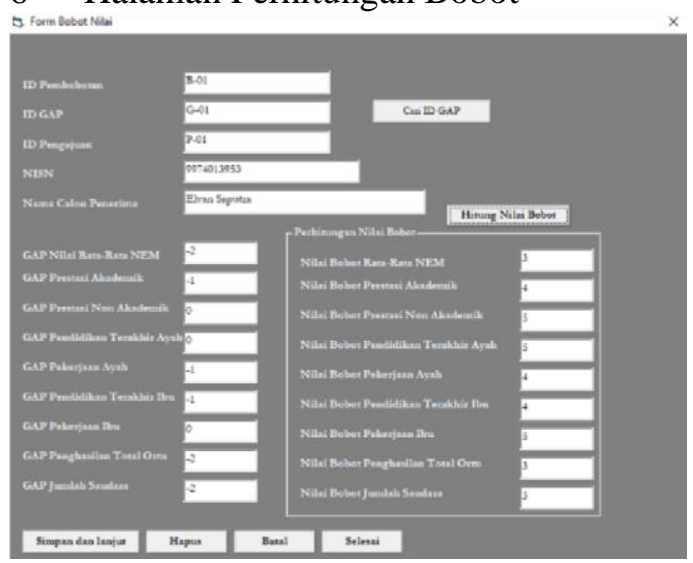

Gambar 7. Desain Halaman Perhitungan Bobot

7 Halaman Perhitungan Akhir

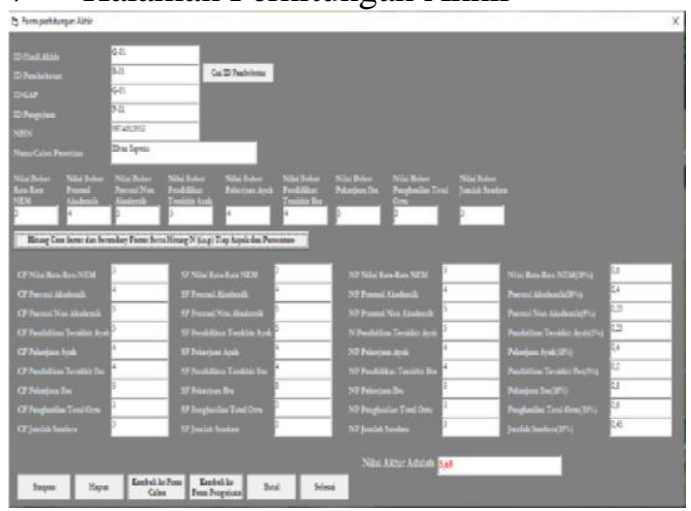

Gambar 8. Desain Halaman Perhitungan Akhir 


\subsection{Tampilan Output}

Tampilan output dari sistem menyajikan data hasil dari perhitungan metode profile matching dengan menampilkan pemeringkatan mahasiswa penerima beasiswa.

UNIVERSITAS

UNIVERSITAS BINA INSAN

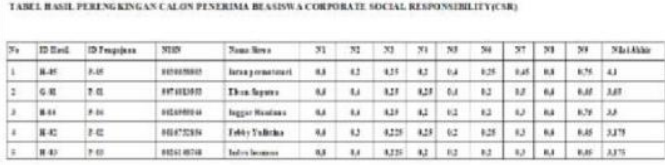

Gambar 8. Desain Peringkat Calon Penerima

\section{KESIMPULAN}

Dari hasil pembahasan yang disebutkan diatas, maka sistem ini memberikan keandalan dalam menentukan beasiswa CSR. 9 kriteria penilaian menjadi masukan untuk diolah dengan menggunakan metode profile matching menggunakan visual basic.

\section{SARAN}

Kepada semua pihak yang berniat untuk mengadakan penelitian dengan tema serupa ,disarankan untuk memberikan tamhahan pengembangan sistem secara online.

\section{DAFTAR PUSTAKA}

[1] Kemendikbud, UU No. 20 Tahun 2003 Tentang Sistem Pendidikan Nasional. UU No. 20 Tahun 2003 Tentang Sistem Pendidikan Nasional, 2003.

[2] A. T. Susilo, "Penerapan Metode Profile Matching Pada Sistem Pendukung Keputusan Pemilihan Ketua Program Studi (STUDI Kasus : Program Studi Teknik Informatika STMIK Musi Rawas)," JUITA J. Inform., vol. 05, no. 02, p. 87, 2018.
[3] E. Muniarsih, Buku Pintar Beasiswa. Jakarta: Gagas Media, 2009.

[4] D. P. Sari, "Penerapan Metode Saw (Simple Additive Weighting) Dalam Sistem Pendukung Keputusan Untuk Menentukan Penerima Beasiswa Pada Smk N 2 Payakumbuh," J. JClick J. Sist. Inf. dan Manaj. Inform., vol. 05, no. 02, pp. 207-216, 2018.

[5] S. A. Rikhaldi, Perancangan Sistem Informasi dan Aplikasinya. Yogyakarta, Indonesia: Informatika, 2017.

[6] T. Efraim, Decision Support Systems and Intelligent Systems. Yogyakarta: Andi, 2005.

[7] Kusrini, Konsep dan Aplikasi Sistem Pendukung Keputusan. Yogyakarta, Indonesia: Andi, 2007.

[8] A. Nugroho, Analisis dan Perancangan Sistem Informasi Dengan Metodologi Berorientasi Objek. Bandung: Informatika, 2018. 